\title{
Larval habitats characteristics of Culicinae subfamily in the south of Iran
}

\author{
S. DOOSTI ${ }^{1,2, \vartheta}$, M.R. YAGHOOBI-ERSHADI ${ }^{2}$, M.M. SEDAGHAT ${ }^{2}$, K. AKBARZADEH ${ }^{2}$, \\ GIDIGLO NUTIFAFA GODWIN ${ }^{2}$ \\ ${ }^{1}$ Center for Communicable Diseases Control, Ministry of Health. Tehran, Iran. Tel.: +98-81455028, `email: fania2008@gmail.com, sa- \\ doosti@health.gov.ir \\ ${ }^{2}$ Department of Medical Entomology and Vector Control, School of Public Health, Tehran University of Medical Sciences. Tehran, Iran
}

Manuscript received: 19 May 2021. Revision accepted: 7 November 2021

\begin{abstract}
Doosti S, Yaghoobi-Ershadi MR, Sedaghat MM, Akbarzadeh K, Godwin GN. 2021. Larval habitats characteristics of Culicinae subfamily in the south of Iran. Nusantara Bioscience 13: 194-201. Globally, mosquitoes (Diptera: Culicidae) are known vectors of many diseases such as Malaria, Dengue fever, Sindbis, West Nile virus, Rift Vally fever, Japanese encephalitis, and Filariasis. This study aimed to determine larval habitat characteristics of mosquitoes in the south of Iran between 2009 and 2013. The study was carried out in different larval habitats of mosquitoes, and samples were collected using dipping and pipette methods. The larvae were kept in lactophenol solution and transferred to the Medical Entomology of Tehran University of Medical Sciences. Then, microscopic slides were prepared, and species were identified using reliable morphological keys. Characteristics of larval breeding places were investigated based on habitat type, water conditions, vegetation type, and sunlight exposure. A total of 8,188 mosquito larvae were collected from 209 different breeding places. In all, 20 mosquito species belonging to 4 genera were identified. Culex quienquefaciatus, Cx. pipiens, Culiseta longiareolata, Cx. tritaeniorhynchus, Cx. sitiens, Cx. theileri and Aedes caspius were the most common species found in this study. The southern part of Iran has the most wharves and airports. Additionally, there is a high diversity of medically important mosquito species like $C x$. pipiens and $C x$. tritaeniorhynchus, Ae. albopictus and Ae. vexans from the Culicidae family. The species are capable of vectoring various diseases in the southern part of Iran; hence, there is a need for more investigations.
\end{abstract}

Keywords: Culicinae, ecology, mosquito genera

\section{INTRODUCTION}

Generally, mosquitoes act as vectors by transmitting diseases such as Malaria, Dengue fever, Sindbis, West Nile, Rift Valley fever, Japanese encephalitis, and Filariasis (Benelli and Duggan 2018; Suesdek 2019). Mosquitoes' life stages and population dynamics are affected by climatic conditions such as temperature, humidity, and larval habitats. Therefore, the biodiversity and variability of different species of mosquitoes in Iran may be attributed to various climatic conditions as major factors.

About 77 species of Anopheles, Aedes, Culex, Coquillettidia, Mansonia, Psorophora, and Culiseta play important roles in the transmission of dirofilariasis (AzariHamidian et al. 2009). Diroflariasis disease has been studied in many parts of the world, and species such as $C x$. pipiens and $C x$. thieleri are some of the vectors. In addition, West Nile and Sindbis viruses, as well as Dirofilaria immitis (dog heartworm) and D. repens (dirofilariasis), which are transmitted by mosquitoes, have been reported in Iran (Naficy and Saidi 1970; Saidi et al. 1976; Azari-Hamidian et al. 2007). In Iran, West Nile viruses are the most important mosquito-borne viruses, as reported using Enzyme-Linked Immunosorbent Assay (ELISA) and Polymerase Chain Reaction (PCR) from Golestan, Guilan, Isfahan, Kermanshah, Khuzistan, Qom, Razavi Khorasan, and Tehran Provinces (Chinikar et al. 2012, 2013a; ShahHosseini et al. 2014; Meshkat et al. 2015). Recently, Shah-
Hosseini et al. (2017) and Bagheri et al. (2015) showed that Cx. pipiens and Ae. caspius s.l. were infected with West Nile viruses in Guilan and West Azerbaijan provinces, respectively. Also, Azari-Hamidian et al. (2009) demonstrated that An. maculipennis and Cx. thieleri are vectors of Setaria and Dirofilaria immitis in the Ardebil province.

Many studies have identified various species of mosquitos in Iran (Zaim 1987a; Vatandoost et al. 2004, 2006; Moosa-Kazemi et al. 2009; Azari-Hamidian 2011; Oshaghi et al. 2011; Hanafi-Bojd et al. 2017; AzariHamidian et al. 2019). The Culicidae family is divided into Anophelinae and Culicinae subfamilies, which include 11 tribes and 41 or 113 genera and 3,563 species (Harbach 2018). The Culicinae subfamily is the largest group of mosquitoes and includes more than 3,075 species in 110 genera (http://mosquito-taxonomic-inventory info). The Culex genus has a worldwide distribution and is divided into 26 subgenera with 769 species. According to investigations by Zaim and Cranston (1986), the Culicinae subfamily includes 33 species (10 species of Aedes, 19 species of Culex, 3 species of Culiseta, and 1 species of Uranotaenia) in Iran. Also, in a recent study, 20 species of Culex were recorded in Iran (Azari-Hamidian and Harbach 2009). In addition to morphological studies, molecular studies can also solve many complex problems in the classification and taxonomy of mosquitoes (Oshaghi et al. 2008; Djadid et al. 2009). Mosquitos usually choose specific larval habitats for oviposition. Most information on Culicinae focused on 
detecting the diversity and variety of species. However, there is little information about the ecology and characteristics of larval habitats. Many factors, such as temperature, $\mathrm{pH}$, salinity, and organic matter, influence larval stage distribution (Muirhead 1951; Clements 1992).

Additionally, water is essential for breeding mosquitoes and affects the growth and development of larval stages. Some compounds such as sodium, potassium, calcium, and dissolved oxygen significantly correlate with the density of specific species (Sasikumar et al. 1986; Piyaratne et al. 2005; Surendran and Ramasamy 2005). Lotfi (1970, 1973, 1976) studied ecological aspects like water temperature and $\mathrm{pH}$ of the breeding places of Culex species. Also, YaghoobiErshadi et al. (1986) studied the characteristics of larval breeding sites in the Minab and Hormozgan provinces. Zaim (1987b) reviewed the larval breeding places and distribution of Iranian Culicinae. Azari-Hamidian et al. (2002) investigated mosquito species, characteristics of larval breeding places, and species diversity of Culex in Rasht province. Also, in several studies by Nikookar et al. (2015a,b, and 2017), mosquitoes' larval habitat characteristics and biodiversity in Mazandaran province were investigated. Currently, there is no updated information on Culicinae and larval habitats in Iran. Hence, this article aimed to investigate the characteristics of mosquitoes' larval habitat in southern Iran.

\section{MATERIALS AND METHODS}

\section{Study area}

The selected study areas included Sistan and Baluchestan, Hormozgan, Khuzistan, Ilam, South Khorasan, Kerman, and
Fars provinces. These areas are bounded by Iraq, Saudia Arabia, Pakistan, and Afghanistan and are located in arid and semi-arid regions. Due to the existence of different climatic conditions in the areas, different larval habitats were found. The field study was conducted in different parts of rural and urban areas between May and September of 2009-2013, with 18 rounds of sampling.

\section{Sampling method}

Sampling was carried out using dipping and pipette methods. Mosquito larvae were collected from natural breeding sites such as river edges, river bed pools, rain pools, marshes, grasslands, tree holes, and artificial breeding sites such as rice fields, irrigation channels, wells, discarded tires, buckets and old tires (Figure 1). For each habitat, sampling was done about 2 to 3 times.

Characteristics of the larval habitats such as the kind of habitat (natural or artificial), habitat situation (permanent or transient, standing or running), vegetation type (with or without vegetation), bottom type, water temperature, water situation (clear or turbid) and sunlight situation (full or partial sunlight or shaded) were recorded. The larvae were preserved in $100 \%$ lactophenol solution. The details (collector's name, date of collection, name of location, type of habitat) were recorded on tubes and then transferred to the Medical Entomology laboratory of Tehran University of Medical Sciences. Larvae were then identified morphologically using reliable keys of Harbach (1985), Zaim and Cranston (1986), and Azari-Hamidian and Harbach (2009). Then, slides of the third and fourth instars larvae were prepared using Berlese's Fluid medium, and specimens were studied under the microscope using $10 \mathrm{X}$ and 40X magnifications.
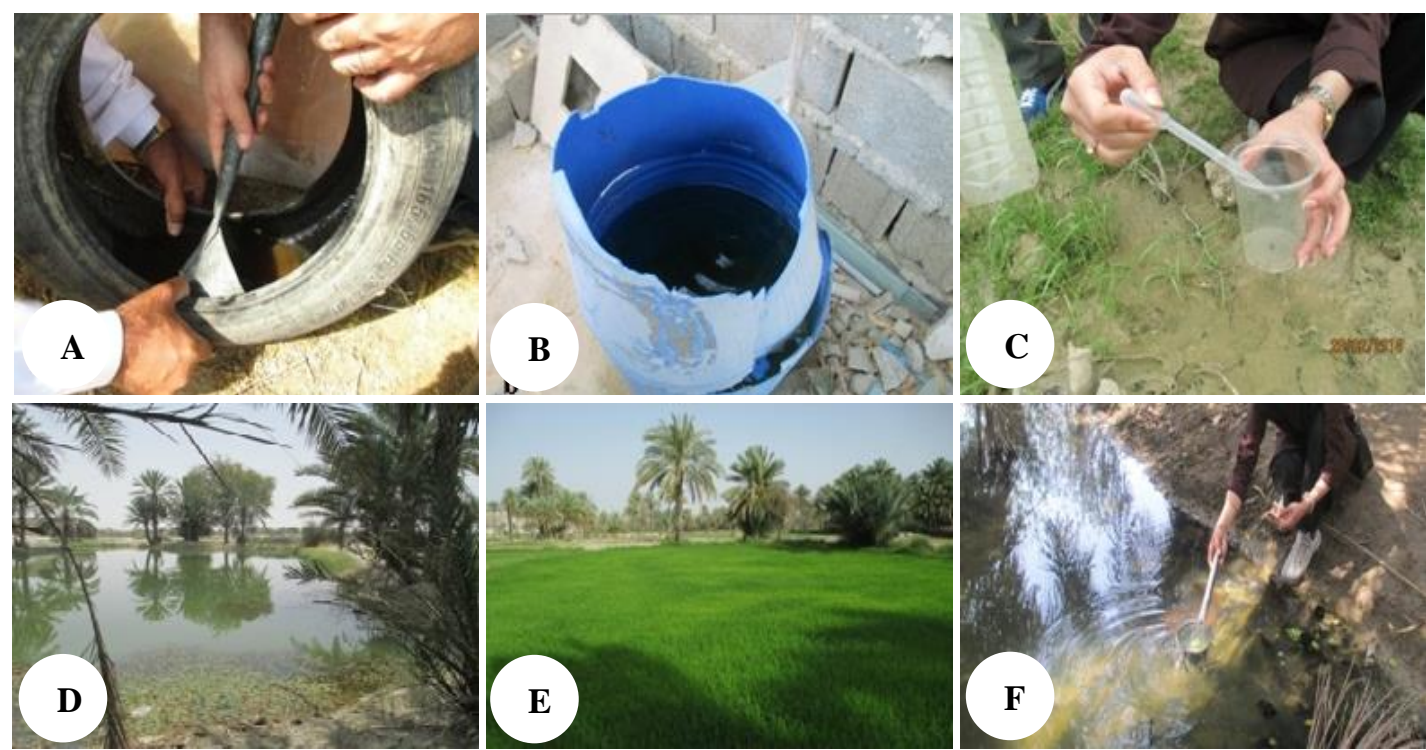

Figure 1. Some larval breeding places for sampling in southern Iran, 2009-2013. A. Old tire, B. Man-made container, C. Irrigation channel, D. Rain pool (Hootak), E. Rice field, F. River edge 


\section{RESULTS AND DISCUSSION}

\section{Results}

This study was conducted from 2009 to 2013 in the southern provinces of Iran (Figure 2), with 8,188 mosquito larvae belonging to four genera: Culex, Aedes, Culiseta, and Uranotaniya were collected. Larvae identified using morphological keys included 13 species of the Culex genus, 5 species of the Aedes genus, one Culiseta genus, and one Uranotaeniya genus (Table 1).

Among the mosquito species found, Culex quinquefasciatus had the highest distribution (2010, $24.55 \%$ ). This species was the most abundant specimen collected alongside other species from natural and artificial larval habitats. Also $\mathrm{Cu}$. longiareolata were the secondhighest in distribution and were also collected from most larval habitats. Overall, 4,997 specimens from natural larval habitats and 3,191 from artificial habitats were collected (Table 2). During this study, $56.05 \%$ of the larvae were collected from temporal larval habitats, compared to those from the permanent habitats $(38.8 \%) ; 4.67 \%$ of them were collected from stagnant water, compared to running water $(0.46 \%)$. In our study, most of the larvae were collected from natural habitats of river edges $(33.58 \%)$ and artificial larval habitats of pools (18.05\%) (Tables 3 and 4).

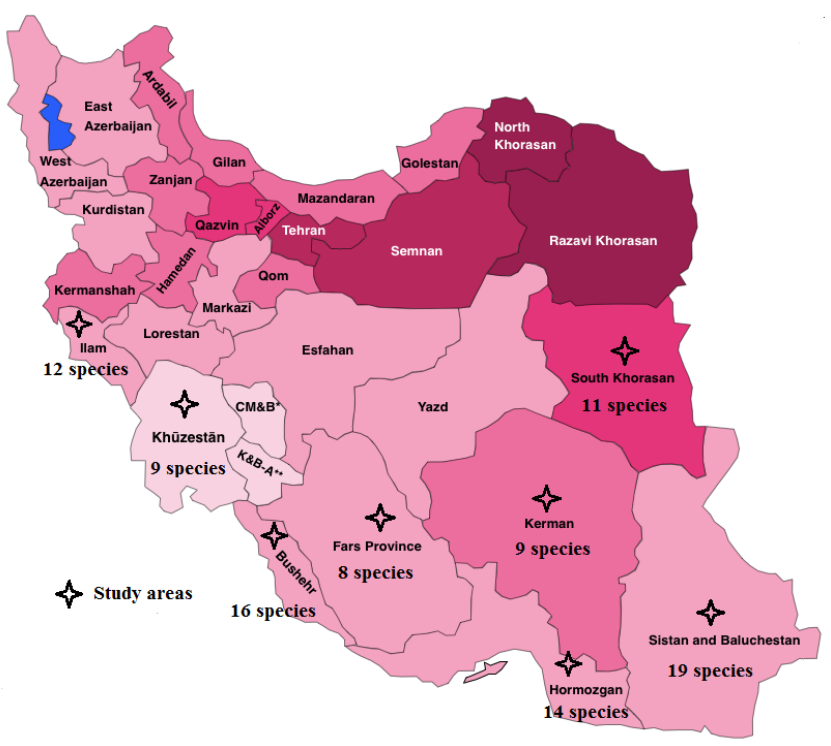

Figure 2. Provinces that were studied for larval collection of the Culicinae subfamily in the southern part of Iran, 2009-2013

Table 1. Frequency of Culicinae subfamily larvae in the south of Iran, 2009-2013

\begin{tabular}{|c|c|c|c|c|c|c|c|c|c|c|}
\hline Species & 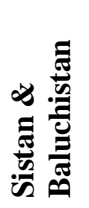 & 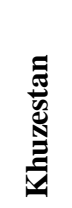 & 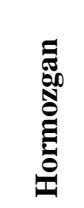 & 茪 & 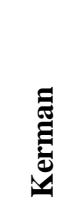 & 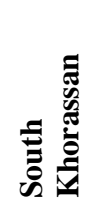 & 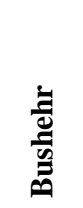 & 志 & हैं & $\Delta^{\circ}$ \\
\hline Cx. arbieeni & 0 & 0 & 2 & 0 & 0 & 0 & 0 & 0 & 2 & 0.02 \\
\hline$C x$. hortensis & 0 & 0 & 0 & 0 & 0 & 40 & 1 & 0 & 41 & 0.50 \\
\hline Cx. pusillus & 0 & 28 & 0 & 1 & 0 & 0 & 63 & 0 & 92 & 1.12 \\
\hline Cx. perexiguus & 121 & 1 & 4 & 180 & 56 & 2 & 51 & 5 & 420 & 5.13 \\
\hline$C x$. pipiens & 55 & 184 & 235 & 19 & 0 & 1 & 522 & 39 & 1055 & 12.88 \\
\hline Cx. theileri & 148 & 9 & 157 & 64 & 0 & 28 & 17 & 21 & 444 & 5.42 \\
\hline Cx. mimiticus & 75 & 0 & 81 & 105 & 19 & 1 & 22 & 0 & 303 & 3.70 \\
\hline CX. sinaiticus & 12 & 0 & 52 & 0 & 0 & 0 & 0 & 0 & 64 & 0.78 \\
\hline Cx. laticinctus & 0 & 0 & 0 & 0 & 4 & 0 & 2 & 0 & 6 & 0.07 \\
\hline Cx. sitiens & 438 & 6 & 0 & 0 & 71 & 0 & 56 & 0 & 571 & 6.97 \\
\hline Cx. tritaeniorhynchus & 311 & 157 & 142 & 9 & 203 & 2 & 5 & 0 & 829 & 10.12 \\
\hline Cx. quinquefasciatus & 1145 & 58 & 135 & 60 & 23 & 0 & 80 & 509 & 2010 & 24.55 \\
\hline Cx. bitaeniorhynchus & 18 & 0 & 0 & 42 & 35 & 0 & 0 & 0 & 95 & 1.16 \\
\hline Cs. longiareolata & 159 & 0 & 648 & 0 & 45 & 825 & 62 & 24 & 1763 & 21.53 \\
\hline Ur. unguiculata & 0 & 6 & 0 & 0 & 0 & 0 & 8 & 0 & 14 & 0.17 \\
\hline Ae. caspius & 113 & 101 & 0 & 0 & 56 & 0 & 165 & 0 & 435 & 5.31 \\
\hline Ae. vexans & 2 & 0 & 26 & 0 & 0 & 0 & 7 & 0 & 35 & 0.43 \\
\hline Ae. flavescens & 2 & 0 & 0 & 0 & 0 & 0 & 0 & 0 & 2 & 0.02 \\
\hline Ae. caballus & 1 & 0 & 1 & 0 & 0 & 0 & 0 & 0 & 2 & 0.02 \\
\hline Ae. albopictus & 5 & 0 & 0 & 0 & 0 & 0 & 0 & 0 & 5 & 0.06 \\
\hline Total & 2605 & 550 & 1483 & 480 & 512 & 899 & 1061 & 598 & 8188 & 100 \\
\hline
\end{tabular}


Table 2. larval habitats characteristics of Culicinae subfamily collected in the southern part of Iran, 2009-2013

\begin{tabular}{|c|c|c|c|c|c|c|c|c|c|c|c|c|c|c|c|c|c|c|c|c|c|}
\hline $\begin{array}{l}\text { Larval habitats } \\
\text { characteristic }\end{array}$ & 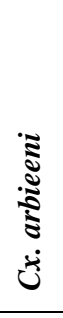 & טు & 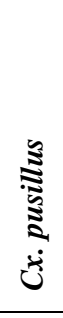 & 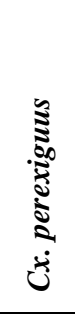 & 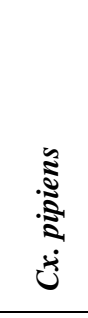 & 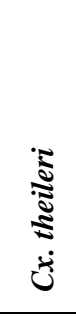 & 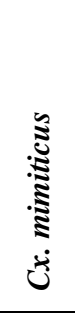 & 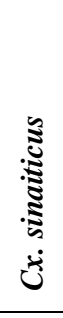 & 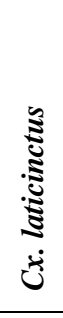 & 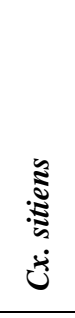 & 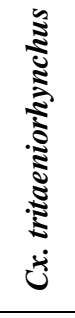 & 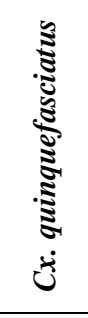 & 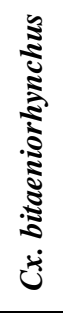 & 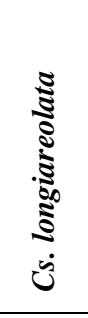 & 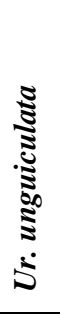 & 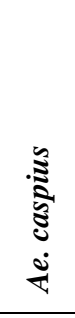 & 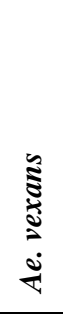 & 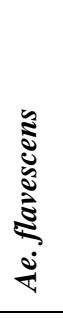 & 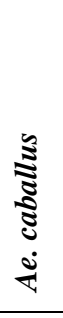 & 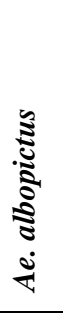 & 苞 \\
\hline \multicolumn{22}{|l|}{ Habitat situation } \\
\hline Permanent & 0 & 36 & 83 & 249 & 331 & 173 & 109 & 8 & 2 & 164 & 388 & 644 & 42 & 825 & 14 & 109 & 0 & 0 & 0 & 0 & 3177 \\
\hline Temporary & 2 & 5 & 8 & 124 & 642 & 250 & 102 & 56 & 4 & 407 & 342 & 1338 & 18 & 938 & 0 & 312 & 35 & 0 & 2 & 5 & 4590 \\
\hline Running water & 0 & 0 & 1 & 43 & 68 & 21 & 88 & 0 & 0 & 0 & 89 & 27 & 35 & 0 & 0 & 9 & 0 & 2 & 0 & 0 & 383 \\
\hline Stagnant water & 0 & 0 & 0 & 4 & 14 & 0 & 4 & 0 & 0 & 0 & 10 & 1 & 0 & 0 & 0 & 5 & 0 & 0 & 0 & 0 & 38 \\
\hline \multicolumn{22}{|l|}{ Vegetation situation } \\
\hline Without & 2 & 25 & 8 & 32 & 728 & 174 & 59 & 17 & 4 & 471 & 89 & 1326 & 0 & 920 & 0 & 31 & 26 & 0 & 0 & 3 & 3915 \\
\hline Out of water & 0 & 0 & 8 & 23 & 19 & 0 & 21 & 0 & 0 & 0 & 131 & 81 & 0 & 270 & 2 & 72 & 0 & 0 & 0 & 0 & 627 \\
\hline In water level & 0 & 1 & 12 & 16 & 63 & 10 & 29 & 2 & 0 & 1 & 90 & 173 & 0 & 150 & 6 & 215 & 2 & 0 & 1 & 0 & 771 \\
\hline Underwater & 0 & 0 & 0 & 106 & 97 & 29 & 64 & 45 & 0 & 0 & 107 & 284 & 37 & 210 & 0 & 26 & 0 & 0 & 1 & 2 & 1008 \\
\hline All types & 0 & 15 & 64 & 243 & 148 & 231 & 130 & 0 & 2 & 99 & 412 & 146 & 58 & 213 & 6 & 91 & 7 & 2 & 0 & 0 & 1867 \\
\hline \multicolumn{22}{|l|}{ Sunlight situation } \\
\hline Full sunlight & 0 & 41 & 67 & 231 & 521 & 365 & 255 & 56 & 6 & 458 & 440 & 940 & 58 & 1421 & 6 & 289 & 33 & 2 & 1 & 3 & 5192 \\
\hline Partial sunlight & 2 & 0 & 18 & 105 & 285 & 52 & 43 & 8 & 0 & 56 & 295 & 495 & 19 & 306 & 6 & 36 & 0 & 0 & 0 & 2 & 1728 \\
\hline \multicolumn{21}{|l|}{ Substrate } & 1267 \\
\hline Muddy & 0 & 40 & 29 & 274 & 635 & 250 & 103 & 27 & 0 & 301 & 614 & 1033 & 41 & 1074 & 14 & 359 & 35 & 2 & 1 & 0 & 4832 \\
\hline Sandy & 2 & 1 & 0 & 62 & 10 & 85 & 96 & 35 & 2 & 108 & 74 & 323 & 38 & 337 & 0 & 76 & 0 & 0 & 1 & 2 & 1252 \\
\hline Rocky & 0 & 0 & 0 & 26 & 143 & 91 & 11 & 2 & 4 & 140 & 22 & 643 & 0 & 172 & 0 & 0 & 0 & 0 & 0 & 0 & 1254 \\
\hline Others & 0 & 0 & 0 & 0 & 267 & 0 & 0 & 0 & 0 & 22 & 0 & 10 & 0 & 51 & 0 & 0 & 0 & 0 & 0 & 3 & 353 \\
\hline All types & 0 & 0 & 63 & 58 & 0 & 18 & 93 & 0 & 0 & 0 & 119 & 2 & 16 & 128 & 0 & 0 & 0 & 0 & 0 & 0 & 497 \\
\hline \multicolumn{22}{|l|}{ Water situation } \\
\hline Turbid & 0 & 5 & 20 & 6 & 334 & 37 & 20 & 24 & 0 & 351 & 176 & 394 & 0 & 264 & 6 & 106 & 26 & 0 & 0 & 0 & 1769 \\
\hline Clear & 2 & 36 & 72 & 414 & 721 & 407 & 283 & 40 & 6 & 220 & 653 & 1616 & 95 & 1499 & 8 & 329 & 9 & 2 & 2 & 5 & 6419 \\
\hline Fresh & 2 & 0 & 29 & 402 & 1045 & 387 & 303 & 60 & 6 & 386 & 812 & 1364 & 95 & 1275 & 14 & 333 & 35 & 2 & 1 & 0 & 6551 \\
\hline Salty & 0 & 41 & 63 & 18 & 10 & 57 & 0 & 4 & 0 & 185 & 17 & 646 & 0 & 488 & 0 & 102 & 0 & 0 & 1 & 5 & 1637 \\
\hline \multicolumn{22}{|l|}{ Habitat kind } \\
\hline Artificial & 2 & 20 & 20 & 85 & 620 & 302 & 13 & 0 & 4 & 377 & 244 & 835 & 23 & 338 & 6 & 290 & 9 & 0 & 0 & 3 & 3191 \\
\hline Natural & 0 & 21 & 72 & 335 & 425 & 142 & 290 & 64 & 2 & 194 & 585 & 1175 & 72 & 1425 & 8 & 145 & 26 & 2 & 2 & 2 & 4997 \\
\hline
\end{tabular}


Table 3. Frequency of larval species of Culicinae subfamily in natural habitats in the southern part of Iran, 2009-2013

\begin{tabular}{|c|c|c|c|c|c|c|c|c|}
\hline \multirow{2}{*}{ Species } & \multicolumn{7}{|c|}{ Natural habitats type } & \multirow{2}{*}{ Total } \\
\hline & River edge & Marsh & Water leakage & Pit & Creek & River bed & Fountain & \\
\hline Cx. hortensis & 0 & 0 & 0 & 1 & 0 & 20 & 0 & 21 \\
\hline CX.pusillus & 0 & 3 & 66 & 0 & 2 & 0 & 1 & 72 \\
\hline Cx. perexiguus & 68 & 73 & 86 & 6 & 17 & 85 & 0 & 335 \\
\hline Cx. pipiens & 55 & 97 & 7 & 185 & 77 & 14 & 0 & 435 \\
\hline Cx. theileri & 3 & 12 & 33 & 8 & 28 & 58 & 0 & 142 \\
\hline CX. mimiticus & 139 & 17 & 23 & 31 & 27 & 53 & 0 & 290 \\
\hline Cx. sinaiticus & 41 & 14 & 0 & 9 & 0 & 0 & 0 & 64 \\
\hline Cx. laticinctus & 0 & 1 & 0 & 0 & 0 & 1 & 0 & 2 \\
\hline Cx. sitiens & 85 & 0 & 108 & 1 & 0 & 0 & 0 & 194 \\
\hline Cx. tritaeniorhynchus & 266 & 38 & 160 & 75 & 42 & 4 & 0 & 585 \\
\hline Cx. quinquefasciatus & 412 & 325 & 249 & 61 & 93 & 35 & 0 & 1175 \\
\hline Cx. bitaeniorhynchus & 35 & 0 & 18 & 0 & 19 & 0 & 0 & 72 \\
\hline Cs. longiareolata & 537 & 195 & 83 & 143 & 228 & 202 & 37 & 1425 \\
\hline Ur. unguiculata & 0 & 0 & 0 & 0 & 8 & 0 & 0 & 8 \\
\hline Ae. caspius & 35 & 0 & 0 & 110 & 0 & 0 & 0 & 145 \\
\hline Ae. vexans & 0 & 0 & 0 & 26 & 0 & 0 & 0 & 26 \\
\hline Ae. flavescens & 2 & 0 & 0 & 0 & 0 & 0 & 0 & 2 \\
\hline Ae. caballus & 0 & 0 & 0 & 2 & 0 & 0 & 0 & 2 \\
\hline Ae. albopictus & 0 & 0 & 0 & 2 & 0 & 0 & 0 & 2 \\
\hline Total & 1678 & 775 & 833 & 660 & 541 & 472 & 38 & 4997 \\
\hline
\end{tabular}

\section{Discussion}

In this study, a total of 8,188 larvae belonging to 4 genera were identified from eight provinces (23 cities) in the southern part of Iran. Our investigations have revealed that of all species collected, larvae from the Culex genus, especially $C x$. quinquefasciatus $(24.55 \%)$ were the most frequent (Table 1). The Culex genus had 768 species, many of which are of biomedical importance (https://www.wrbu.si.edu/vectorspecies/genera/culex). $C x$. quinquefasciatus is an established species worldwide and is usually found in areas with high human populations. Adults easily feed on blood from various vertebrates, including wild and domestic birds, mammals, and humans (Farajollahi et al. 2011). Females are generally active at night and feed both outdoors and indoors. This species is a known agent of diseases such as West Nile virus, Chikungunya virus, Rift Valley Fever, Wuchereria bancrofti, and Avian malaria. Also, Cx. quinquefasciatus was introduced as the main vector of West Nile Virus in Asia (Hubálek and Halouzka 1999). West Nile virus is probably one of the most important mosquito-borne arboviruses in Iran; the virus was identified in 26 out of the 31 provinces of Iran (Ahmadnejad et al. 2011; Chinikar et al. 2013a; Pourmahdi et al. 2013), using a serological technique (ELISA). In line with our study, AzariHamidian et al. (2010) also indicated that $C x$. quinquefasciatus was the main species in the Persian Gulf islands (Qeshm, Lark, and Abu Musa). The breeding places of adults varied but larvae developed in typical habitats such as sewers, ground pools, ditches, agricultural seepage pits, and sewage treatment plant holding tanks. Larvae usually prefer water bodies with high organic content (https://www.wrbu.si.edu/vectorspecies/genera/culex).

Our results show Culex larvae mostly oviposited in natural and artificial habitats. Larvae of $C x$. quinquefasciatus were found in the pools (artificial habitats) and river edges (natural habitats). Some other breeding places of this species are dams, streams, and water leakages. Our studies collected this species from temporal water bodies with full sunlight without vegetation, muddy substrate, and clear and fresh water. This species was mostly reported in the Golestan province from temporal and stagnant water bodies with full sunlight and mud substrate (Sofizadeh et al. 2018). Still, Hanafi-Bojd et al. (2017) reported the presence of this species in permanent water bodies with full sunlight and sandy substrate habitats with clear and fresh water from the Hormozgan province.

In a previous study, $C x$. pipiens were reported as the dominant species, but our study from North Khorasan has shown that the dominant species were $C x$. quinquefasciatus (Azari-Hamidian et al. 2011). This species is widely distributed, and recent studies have demonstrated that $C x$. pipiens is the most prevalent species in Iran (KhoshdelNezamiha et al. 2014; Nikookar et al. 2015a, 2016; Sofizadeh et al. 2017). Cx. pipiens is primarily an ornithophilic species but could feed on humans and other animals that act as vectors of WNV (Fonseca et al. 2004; Weitzel et al. 2015). This species was studied by MousaKazemi et al. (2015) (16.5\%), Nikookar et al. (2018) (69.7\%), Moradi et al. (2018) (58.7\%) and Azari-Hamidian (2011) (10.1\%), and was reported to be the dominant species with a wide distribution in the study area.

Also, studies conducted by Navidpour et al. (2012) have shown that the most frequent mosquito species in the Shadegan (Khuzestan) province were $C x$. pipiens. In Yaghoobi et al. (1986) 's investigations on the biology of mosquitoes in the Minab (Hormozgan) province, some species, such as $C x$. bitaeniorhynchus, Cx.pipiens, $C x$. theileri, $C x$. tritaeniorhynchus, $C x$. perexiguus, $C x$. 
quinquefasciatus, Cx. sinaiticus, Cx. deserticola and Cs. longiareolata were reported, but our studies in some districts of the Hormozgan and Minab provinces have revealed the presence of $C x$. tritaeniorhynchus, Cx. perexiguus, $C x$. quinquefasciatus, Cx.pipiens and Cs. longiareolata.

During our study, larvae of the $C x$. pipiens were collected from natural and artificial breeding places such as pits, marshes, pools, and ovitrap. Previous studies have revealed the existence of $C x$. pipiens in flooded cellars drains, wells, septic tanks, underground drainage systems, abandoned mine tunnels, and coal mines (Horsfall 1955; Cranston et al. 1987; Zaim 1987b; Harbach 1988; Service 1993), whereas in our study, larval habitats of $C x$. pipiens are mostly on a stagnant and artificial freshwater body. The characteristics of larval habitats have shown that $C x$. pipiens usually inhabit different breeding places with various ecological conditions. The situation led to high larval dispersal and distribution from Iran (Azari-Hamidian 2005). In Isfahan, $C x$. pipiens were mostly found in rice fields and natural breeding places (Mousakazemi 2000). This species has been reported in almost all provinces in Iran (AzariHamidian et al. 2005).

In the present study, Culiseta longiareolata had the greatest dispersal among the Culicinae subfamily. There is little information on the ecology of the Culiseta species in Iran. The large geographical distribution of $\mathrm{Cu}$. longiareolata has been reported from the Plaerectic region (Asia and Africa). This species was reported for the first time by Gutsevich in 1943 from the north of Iran. In Iran, five species, including Cs. (Allotheobaldia) longiareolata, Cs. (Cullicella) morsitans, Cs. (Culliseta) alaskensis, Cs. (Cul). annulata and Cs. (Cul) sabochrea have been reported. This species was reported with a higher frequency of collection from different parts of Iran and various larval habitats (Mousakazem 2000; Azari-Hamidian 2005; AzariHamidian et al. 2011; Dehghan et al. 2011). In our study, this species was reported from Hormozgan and South Khorasan provinces but in Golestan provinces, Cs. longiareolata were collected from only larval habitats with cement substrate and without vegetation (Sofizadeh et al. 2018). Our studies have shown that Cs. longiareolata were collected more frequently from temporal and natural habitats $(28.5 \%)$ (River edge, marsh, and water leakage) than from artificial habitats. The larval habitats are mostly in full sunlight, without vegetation, muddy substrate, and clear water.

Though the Aedes group is a large tribe and comprises 1,255 species belonging to 10 genera, there is little information about the Aedes in Iran, and till now, only 12 species have been reported. Ae. Albopictus and Ae. unilineatus were reported for the first time from southern Iran (Doosti et al. 2016). This species is a competent vector of 26 arboviruses, including Dengue fever, WNV, and Chikungunya (Paupy et al. 2009; Bonizzoni et al. 2013). In the present survey, Ae. caspius, Ae. vexans, Ae. flavescens, Ae. caballus, Ae. unilineatus and Ae. albopictus were collected from natural $(177,2.16 \%)$ and artificial (302, $3.68 \%$ ) larval habitats. Ae. caspius is one of the most common mosquitoes distributed throughout the world. As exophagic species often bite indoors and outdoors during the day (especially at dusk). It is a floodwater mosquito and has multiple generations per year. The mosquitoes act as vectors of West Nile, Tahyna, and Isfahan viruses and Francisella tularensis (https://wrbu.si.edu/vectorspecies/mosquitoes/caspius).

Ae. caspius was mainly reported from most regions of Iran (Azari-Hamidian et al. 2010; Moosa Kazemi et al. 2010, 2015; Abai et al. 2016; Sofizadeh et al. 2016). Sofizadeh et al. (2018) reported only Ae. caspius from the Golestan province, but in another study in the Kalaleh county, 3 species (Oc. caspius, Oc. echinus, and Oc. geniculatus) were reported by Sofizadeh et al. (2016). In our study Ae. caspius had the highest frequency of distribution $(435,5.31 \%)$ and was found mostly in artificial habitats $(290,3.54 \%)$ than natural habitats $(145,1.77 \%)$. This species was typically collected from temporal, full sunlight and vegetation within water level, with muddy substrate and clear and fresh water breeding places.

In the Kurdistan province, Ae. caspius was mainly found in river edges with stagnant, clear water and partial sunlight habitats (Banafshi et al. 2013). In the Golestan province, the species preferred temporal, running water, muddy substrate, and full sunlight habitats, similar to our results. Although this species prefers larval habitats with clear and fresh water, it is sometimes collected from larval habitats with turbid and brackish water. Moradi et al. (2018) collected this species from the Ardebil province's natural, temporal and clayey larval habitats.

Many mosquito-borne viruses are endemic in some countries (Parhizgari et al. 2017). Many barriers, such as a change in the behavior of vectors, the landscape of disease epidemiology, climate change, the lifestyle of community members, illegal emigration, and war, have made preventing and controlling the diseases they transmit difficultly. Although there is information on malaria vectors in Iran, little is known about publications on the Culicinae family until now. Because of the emerging and remerging diseases caused by vectors, especially mosquito-borne pathogens, it is necessary to monitor mosquitoes with improved systems. Therefore, it is essential to study many different aspects of the ecology and behavior of vectors to plan and execute effective mosquito surveillance.

\section{ACKNOWLEDGEMENTS}

We are grateful to the Center of Health Services staff for their assistance in the fieldwork and to some community members for their cooperation during the survey. This research was financially supported by the Iran National Science Foundation (INSF) (project no 86052/18) and partly by the Tehran University of Medical Sciences (grant no 8803-27-9200). We also appreciate the Tehran University of Medical Sciences for its unflinching support. The authors would like to thank Dr. S. Azari Hamidian for providing useful comments and reviewing the papers. The authors declare that there is no conflict of interest. 


\section{REFERENCES}

Abai MR, Saghafipour A, Ladonni H, Jesri N, Omidi S, Azari-Hamidian S 2016. Physicochemical characteristics of larval habitat waters of mosquitoes (Diptera: Culicidae) in Qom Province, Central Iran. J Arthropod-Borne Dis 10 (1): 65-77.

Ahmadnejad F, Otarod V, Fallah MH, Lowenski S, Sedighi-Moghaddam R, Zavareh A, Durand B, Lecollinet S, Sabatier P. 2011. Spread of West Nile virus in Iran: A cross-sectional serosurvey in equines, 2008 2009. Epidemiol Infect 139: 1587-1593. DOI $10.1017 / \mathrm{S} 0950268811000173$

Azari-Hamidian S, Abai MR, Arzamani K, Bakhshi H, Karami H, Ladonni H, Harbach RE. 2011. Mosquitoes (Diptera: Culicidae) of North Khorasan Province, Northeastern Iran and the zoogeographic affinities of the Iranian and Middle Asian Mosquito Fauna. J Entomol 8 (3): 204 217. DOI: $10.3923 /$ je.2011.204.217.

Azari-Hamidian S, Behzad N, Ralph EH. 2019. A detailed review of the mosquitoes (Diptera: Culicidae) of Iran and their medical and veterinary importance. Acta Tropica 194: 106-122. DOI 10.1016/j.actatropica.2019.03.019.

Azari-Hamidian S, Harbach RE. 2009. Keys to the adult females and fourthinstar larvae of the mosquitoes of Iran (Diptera: Culicidae). Zootaxa 2078: 1-33. DOI: 10.11646/zootaxa.2078.1.1.

Azari-Hamidian S, Joefshani MA, Moss-lem M. 2005. Mosquitoes fauna and distribution of the genus Culex (Diptera: Culicidae) in Guilan Province. Pajouhesh Sazandegh 68: 39-45. [Persian]

Azari-Hamidian S, Linton YM, Abai MR, Ladonni H, Oshaghi MA Hanafi-Bojd AA, Moosa-Kazemi SH, Shabkhiz H, Pakari A, Harbach RE. 2010. Mosquito (Diptera: Culicidae) fauna of the Iranian islands in the Persian Gulf. $J$ Nat His 44: 913-925. DOI: 10.1080/00222930903437358

Azari-Hamidian S, Yaghoobi-Ershadi MR, Javadian E, Mobedi I, Abai MR, Linton YM, Harbach RE. 2009. Distribution and ecology of mosquitoes in a focus of dirofilarasis in northwestern Iran, with the first finding of filarial larvae in naturally infected local mosquitoes. Med Vet Entomol 23: 111-121. DOI: 0.1111/j.1365-2915.2009.00802.x.

Azari-Hamidian S, Yaghoobi-Ershadi MR, Javadian E. 2002. The distribution and larval habitat characteristics of mosquitoes (Diptera: Culicidae) in Rasht County (Guilan Province, Iran). Modarres J Med Sci 4: 87-96

Azari-Hamidian S. 2005. Larval habitat characteristics of mosquitoes of the ge-nus Culiseta Felt, 1904 (Diptera: Cu-licidae) in the Caspian Sea littoral, Iran. Zool Middle East 36 (1): 59-66. DOI 10.1080/09397140.2005.10638128.

Azari-Hamidian S. 2007. Checklist of Iranian mosquitoes (Diptera: Culicidae). J Vect Ecol 32 (2): 235-242. DOI: 10.3376/1081-1710 (2007) 32 [235: coimdc] 2.0.co; 2.

Azari-Hamidian S. 2011. Larval habitat characteristics of the genus Anopheles (Diptera: culicidae) and a checklist of mosquitoes in Guilan Province, northern Iran. Iran J Arthropod Borne Dis 5 (1): 37-53.

Bagheri M, Terenius O, Oshaghi MA, Motazakker M, Asgari S, Dabiri F, Vatandoost H, Mohammadi BM, Chavshin AR. 2015. West Nile virus in mosquitoes of Iranian wetlands. Vector-Borne Zoonotic Dis 15: 750754. DOI: $10.1089 /$ vbz.2015.1778.

Banafshi O, Abai MR, Ladonni H, Bakh-shi H, Karami H, Azari-Hamidian S. 2013. The fauna and ecology of mosquito larvae (Diptera: Culicidae) in western Iran. Turk J Zool 37: 298-307.

Benelli G, Duggan MF. 2018. Management of arthropod vector data - social and ecological dynamics facing the One Health perspective. Acta Trop 182: 80-91. DOI: 10.1016/j.actatropica.2018.02.015.

Bonizzoni M, Gasperi G, Chen X, James AA. 2013. The invasive mosquito species Aedes albopictus: Current knowledge and future pers-pectives. Trends Parasitol 29 (9): 460-468. DOI: 10.1016/j.pt.2013.07.003.

Chinikar S, Javadi A, Ataei B, Shakeri H, Moradi M, Mostafavi E, Ghiasi SM. 2012. Detection of West Nile virus genome and specific antibodies in Iranian encephalitis patients. Epidemiol Infect 140: 1525-1529. DOI: $10.1017 / \mathrm{S} 0950268811002056$

Chinikar S, Shah-Hosseini N, Mostafavi E, Moradi M, Khakifirouz S, Jalal T, Goya MM, Shirzadi MR, Zainali M, Fooks AR. 2013a. Seroprevalence of West Nile virus in Iran. Vector-Borne Zoonotic Dis 13: 586-589. DOI: $10.1089 / \mathrm{vbz} .2012 .1207$

Clements AN. 1992. The Biology of Mosquitoes Volume 1. Development, Nutrition and Reproduction. Chapman and Hall, London.

Cranston PS, Ramsdale CD, Snow KR, White GB. 1987. Keys to the Adults, Male Hypopygia, Fourth-Instar Larvae and Pupae of the British
Mosquitoes (Culicidae) with Notes on their Ecology and Medical Importance. Fresh Water Biological Association Scientific Publication, Cumbria.

Dehghan H, Sadraei J, Moosa-Kazemi SH, Davari B. 2011. Ecological study of Culex pipiens, the dominant species of Culicidae mosquitoes and its control solutions in Yazd Province. Sci J Kurdistan Uni Med Sci 15 (4): 81-88. [Persian]

Djadid ND, Jazayeri H, Gholizadeh S, Rad ShP, Zakeri S. 2009. First record of a new member of Anopheles Hyrcanus Group from Iran: Molecular identification, diagnosis, phylogeny, status of $\mathrm{kdr}$ resistance and Plasmodium infec-tion. J Med Entomol 46: 1084-1093. DOI: 10.1603/033.046.0515.

Doosti S, Yaghoobi-Ershadi MR, Schaffner F, Moosa-Kazemi SH, Akbarzadeh K, Gooya MM, Vatandoost H, Shirzadi MR, Mostafavi E. 2016. Mosquito surveillance and the first record of the invasive mosquito species Aedes (Stegomyia) albopictus (Skuse) (Diptera: Culicidae) in southern Iran. Iran J Publ Health 45 (6): 1064-1073.

Farajollahi A, Fonseca DM, Kramer LD, Kilpatrick AM. 2011. "Bird biting" mosquitoes and human disease: A review of the role of Culex pipiens complex mosquitoes in epidemiology. Infect Genet Evol 11 (7): 1577-1585. DOI: 10.1016/j.meegid.2011.08.013.

Fonseca DM, Keyghobadi N, Malcolm CA, Mehmet C, Schaffner F, Mogi M, Fleischer RC, Wilkerson RC. 2004. Emerging vectors in the Culex pipiens complex. Sci 303: 1535-1538. DOI: 10.1126/science.1094247.

Gutsevich AV. 1943. On the mosquitoes of North Iran. Comtes Rendus Academic Science URSS. XL (3): 123-125.

Hanafi-Bojd AA, Soleimani-Ahmadi M, Doosti S, Azari-Hamidian S. 2017. Larval habitats, affinity and diversity indi-ces of Culicinae (Diptera: Culicidae) in southern Iran. Intl J Mosq Res 4 (2): 27-38.

Harbach RE. 1985. Pictorial keys to the genera of mosquitoes, subgenera of Culex and the species of Culex (Culex) occurring in south-western Asia and Egypt, with a note on the subgeneric placement of Culex deserticula (Diptera:Culicidae). Mosq Sys 17 (2): 83-107.

Harbach RE. 1988. The mosquitoes of the subgenus Culex in southwestern Asia and Egypt (Diptera: Culicidae). Contrib Am Entomol Inst 24: 1 240.

Harbach RE. 2018. Mosquito Taxonomic Inventory. http://mosquitotaxonomic-inventory info/. Accessed 29 July, 2018.

Horsfall WR. 1955. Mosquitoes. Their Bionomics and Relation to Disease. Hafner Publishing, New York.

Hubálek Z, Halouzka J. 1999. West Nile fever - a reemerging mosquitoborne viral disease in Europe. Emerg Infect Dis 5: 643-650. DOI: 10.3201/eid0505.990505

Khoshdel-Nezamiha F, Vatandoost H, Azari-Hamidian S, Mohammadi Bavani M, Dabiri F, Entezar-Mahdi R, Chavshin AR. 2014. Fauna and larval habitats of mosquitoes (Diptera: Culicidae) of West Azerbaijan. J Arthropod Borne Dis 8 (2): 163-173.

Lotfi MD. 1970. Iranian species of genus Culex ([Culinae]: Diptera). Bull de la Soci de Patho Exoti 63: 399-403.

Lotfi MD. 1973. Iranian species of genus Culex (Culicinae: Diptera) II. Report of four species of larvae (including three new records) and 14 adult species. Bull de la Soci de Patho Exoti 66: 204-207.

Lotfi MD. 1976. Key to Culicinae of Iran, genus Culex and their biology (Diptera: Culicidae). Iranian J Publ Health 5: 71-84.

Meshkat Z, Chinikar S, Shakeri MT, Manavifar L, Moradi M, Mirshahabi H, Jalili T, Khakifirouz S, Shahhosseini N. 2015. Prevalence of West Nile virus in Mashhad, Iran: A population-based study. Asian Pac J Trop Med 8: 203-205. DOI: 10.1016/S1995-7645(14)60315-1.

Moosa-Kazemi S, Vatandoost H, Nikookar H, Fathian M. 2009. Culicinae (Diptera: Culicidae) mosquitoes in chabahar County, Sistan and Baluchistan Province, Southeastern Iran. Iran J Arthropod Borne Dis 3 (1): 29-35.

Moosa-Kazemi SH, Karimian F, Davari B. 2010. Culicinae mosquitoes in Sanan-daj County, Kurdistan Province, Eastern Iran. J Vector Borne Dis 47 (2): 103-107.

Moosa-Kazemi SH, Zahirnia AH, Sharifi F, Davari B. 2015. The fauna and ecology of mosquitoes (Diptera: Culicidae) in Western Iran. Arthropod Borne Dis 9 (1): 49-59.

Moradi-Asl E, Hazrati S, Vatandoost H, Emdadi D, Ghorbani E, Ghasemian A, Rafiee M, Panahi A, Shokri A. 2018. Fauna and larval habitat characteristics of mosquitoes (Diptera: Culicidae) in Ardabil Province, Northwestern Iran. J Health 9: 259-266.

Mousakazemi S, Zaim M, Zahraii A. 2000. Fauna and ecology of Culicidae of the Zarrin- Shahr and Mobarakeh area in Isfahan Province. Armaghan Danesh J Yasuj Univ Med Sci 5: 46-54. [Persian] 
Muirhead-Thomson RC. 1951. Mosquito Behaviour in Relation to Malaria Transmission and Control in the Tropics. Edward Arnold and Co, London.

Naficy K, Saidi S. 1970. Serological survey on viral antibodies in Iran. Trop Geogr Med 2: 183-188.

Navidpour S, Vazirianzadeh B, Harbach R, Jahanifard E, Moravvej SA 2012. The identification of culicine mosquitoes in the Shadegan wetland in southwestern Iran. J Insect Sci 12: 105. DOI: 10.1673/031.012.10501

Nikookar S, Fazeli-Dinan M, Azari-Hamidian S, Mousavinasab S, Arabi N Ziapour S, Shojaee J, Enayati AA. 2017. Species composition and abundance of mosquito larvae in relation with their habitat characteristics in Mazandaran Province, northern Iran. Bull Entomol Res: 1-13. DOI: 10.1017/S0007485317000074.

Nikookar SH, Azari-Hamidian S, Fazeli-Dinan M, Nasab SNM, Aarabi M, Ziapour SP, Enayati A. 2016. Species composition, co-occurrence, association and affinity indices of mosquito larvae (Diptera: Culicidae) in Mazandaran Province, northern Iran. Acta trop 157: 20-29. DOI: 10.1016/j.actatropica.2016.01.014

Nikookar SH, Fazeli-Dinan M, Azari-Hamidian S, Mousavi NSN, Aarab M, Ziapour SP, Enayati AA, Hemingway J. 2018. Fauna, ecological characteristics, and checklist of the mosquitoes in Mazandaran Province, Northern Iran. Med Entomol 55: 634-645. DOI: 10.1093/jme/tjx228.

Nikookar SH, Moosa-Kazemi SH, Oshaghi MA, Vatandoost H, Yaghoobi Ershadi MR, Enayati AA, Motevali-Haghi M, Ziapour SP and FazeliDinan M. 2015b. Biodiversity of culicid mosquitoes in rural Neka township of Mazandaran province, Northern Iran. J Vector Borne Dis 52 (1): 63-72.

Nikookar SH, Moosa-Kazemi SH, Yaghoobi-Ershadi MR, Vatandoost H, Oshaghi MA, Ataei A, Anjamrooz M. 2015a. Fauna and larval habitat characteristics of mosquitoes in Neka county, Northern Iran. J Vector Borne Dis 9 (2): 253-266.

Oshaghi MA, Vatandoost H, Gorouhi A, Abai MR, Madjidpour A, Arshi S, Sadeghi H, Nazari M, Mehravaran A. 2011. Anopheline species composition in borderline of Iran-Azerbaijan. Acta Trop 119 (1): 44 49. DOI: 10.1016/j.actatropica.2011.04.005.

Oshaghi MA, Yaghobi-Ershadi MR, Shemshad Kh, Pedram M, Amani H. 2008. The Anopheles superpictus complex: Introduction of a new malaria vec-tor complex in Iran. Bull Soc Pathol Exot 101: 429-434

Parhizgari N, Gouya MM, Mostafavi E. 2017. Emerging and re-emerging infectious diseases in Iran. Iran J Microbiol 9: 122-142.

Paupy C, Delatte H, Bagny L, Corbel V, Fontenille D. 2009. Aedes albopictus, an arbovirus vector: from darkness to the light. Microbes Infect 11 (14-15): 1177-185. DOI: 10.1016/j.micinf.2009.05.005.

Piyaratne MK, Amerasinhe FP, Amerasinghe PH, Konradsen F. 2005 Physico-chemical characteristics of Anopheles culicifacies and Anopheles varuna breeding water in a dry zone stream in Sri Lanka. J Vect Born Dise 42 (2): 61-67.

Pourmahdi BM, Ghadrdan MAR, Seif ASMR, Zeinvand M. 2013. A serological survey on antibodies against West Nile virus in horses of Khuzestan Province. Iran J Vet Med 7: 185-191.

Province, Northwestern Iran. J Arthropod Borne Dis 8: 163-173.

Res 114: 289-295.

Saidi S, Tesh R, Javadian E, Nadim A. 1976. The prevalence of human infection with West Nile virus in Iran. Iran J Publ Health 5 (1): 8-13.
Sasikumar PS, Suryanarayanan P, Thomas C, Kalyanaraman K, Prasad RS. 1986. Influence of certain physic-chemical factors upon the larval population of Mansonia mosquitoes (Culicidae: Diptera) in Trivandrum City, India. Proc Indian Acad Sci 95: 549-555.

Service MW. 1993. Mosquitoes (Culicidae). In: Lane RP, Crosskey RW (eds). Medical Insects and Arachnids. Chapman and Hall, London.

Shah-Hosseini N, Chinikar S, Ataei B, Fooks AR, Groschup MH. 2014. Phylogenetic analysis of West Nile virus genome, Iran. Emerg Infect Dis 20: 1419-1421. DOI: 10.3201/eid2008.131321.

Shah-hosseini N, Chinikar S, Mossa-Kazemi SH, Sedaghat MM, Kayedi MH, Luh-ken R, Schmidt-Chanasit J. 2017. West Nile Virus lineage-2 in Culex specimens from Iran. Trop Med Intl Health 22 (10): 13431349. DOI: $10.1111 /$ tmi.12935.

Sofizadeh A, Edalat H, Abai MR, Hanafi-Bojd AA. 2016. Fauna and some biological characteristics of Anopheles mosquitoes (Diptera: Culicidae) in Kalaleh County, Golestan Province, northeast of Iran. Asian Pac J Trop Biomed 6 (9): 730-734. DOI: 10.1016/j.apjtb.2016.07.005.

Sofizadeh A, Moosa-Kazemi SH, Dehghan H. 2017. Larval habitats characteristics of mosquitoes (Diptera: Culicidae) in north-east of Iran. J Arthropod Borne Dis 27 (2): 211-225.

Sofizadeh A, Shoraka HR, Mesgarian F, Ozbaki GM, Gharaninia AS, Sahneh E, Dankoob R, Malaka A, Fallah S, Nemani SH. 2018. Fauna and larval habitats characteristics of mosquitoes (Diptera: Culicidae) in Golestan Province, Northeast of Iran, 2014-2015. J Arthropod-Borne Dis 12 (3): 240-251. DOI: 10.18502/jad.v12i3.76.

Suesdek L. 2019. Microevolution of medically important mosquitoes - a review. Acta Trop 191: 162-171 DOI: 10.1016/j.actatropica.2018.12.013.

Surendran SN, Ramasamy R. 2005. Some characteristics of the larval breeding sites of Anopheles culicifacies species B and E in Sri Lanka. J Vect Borne Dis 42: 39-44.

Vatandoost H, Oshaghi MA, Abaie MR, Shahi M, Yaaghoobi F, Baghaii M, Hanafi-Bojd AA, Zamani G, Townson H. 2006. Bionomics of Anopheles stephensi Liston in the malarious area of Hormozgan Province, southern Iran, 2002. Acta Trop 97 (2): 196-203. DOI: 10.1016/j.actatropica.2005.11.002.

Vatandoost H, Shahi H, Abai MR, Hanafi-Bojd AA, Oshaghi MA, Zamani G. 2004. Larval habitats of main malaria vectors in Hormozgan Province and their susceptibility to different larvicides. Southeast Asian J Trop Med Public Health 35 (2): 22-25.

Weitzel T, Jawien P, Rydzanicz K, Lonc E, Becker N. 2015. Culex pipiens s.l. and Culex torrentium (Culicidae) in Wroclaw area (Poland): Occurrence and breeding site preferences of mosquito vectors. Parasitol Res 114 (1): 289-95. DOI: 10.1007/s00436-014-4193-1.

Yaghoobi-Ershadi MR, Zaim M, Manouchehri AV. 1986. Studies on the biology of the mosquitoes in the districts of Minab, Hormozgan province, Iran (1983-84). 1- Characteristics of the larval breeding sites. J Environ 13: 17-39. [Persian].

Zaim M, Cranston PS. 1986. Checklist and keys to the Culicinae of Iran (Diptera; Culicidae). Mosq Syst 18: 233-245.

Zaim M. 1987a. The mosquito fauna of Kashan, public health importance and control. Desert Sci Res 18: 1-41. [Persian].

Zaim M. 1987b. The distribution and larval Habitat characteristics of Iranian Culicinae. J Am Mosq Control Assoc 3 (4): 573-588. 